\title{
Zero-One Programming Model \\ for Daily Operation Scheduling of Irrigation Canal
}

\author{
B.R.Ramesh \\ Assistant Professor, Civil Engineering Department \\ Bapuji Institute of Engineering and Technology \\ Davanagere 577 004, Karnataka, India \\ Tel: 91-8192-223-259Ｅ-mail: brrbiet@yahoo.com \\ K. Venugopal \\ Institute of Remote Sensing, College of Engineering -Guindy \\ Anna University, Chennnai, India \\ K. Karunakaran \\ Centre for Water Resources, College of Engineering -Guindy \\ Anna University, Chennnai, India
}

\begin{abstract}
Irrigation scheduling is one of the important managerial activities that aim at effective and efficient utilization of water. A number of scheduling techniques are available today. Despite this, irrigation scheduling is only at inception level in most of developing countries. In India also there are many methods of irrigation scheduling to canals are available. The drawback of this method of operation of laterals is highlighted in this paper. Further, operations of the laterals are to be simple so that the system can be managed easily. In addition, the supply to laterals should match with the day supply in the canal and total supply for the period. In this paper a Mixed Linear Integer Programming model is described, which aims at daily scheduling of laterals from the canal considering the constraints of the system. It is proposed to run the laterals, (except a lateral which is proposed to operate at variable discharge) either full/half or closed condition for making the laterals operation simple. This Zero-One Mixed Linear Integer Programming model is applied to a field problem to derive daily operation scheduling of laterals of the system.
\end{abstract}

Keywords: Water allocation, Optimization model, Canal operation, Irrigation water, Scheduling, Zero-One programming

\section{Introduction}

Irrigation scheduling is the use of water management strategies to prevent over-application of water while minimizing yield loss due to water shortage or drought stress. Irrigation scheduling will ensure that water is applied to the crop when needed and in the amount needed. (Solanki.A.S -2003). Effective irrigation scheduling requires reliable and timely water delivery through coordinated action between the supplier and the user. However, allocation and delivery of water, particularly in large canal systems, is much more complex and difficult than commonly recognized. It involves complicated social, organizational, legal and economic questions in addition to the technical matters. Manual control, Automatic on site-operation of a control structure, fixed method of operation control structures are some of the alternative methods of operation of canal on basis of control of hydraulic structures adopted in scheduling warabandi, osrabandi, shejpali, block and satta system are some of the methods adopted in India in canal system operation. Also in canal operation, significant progress has been made using computer facilities, information techniques, measurements, canal control concepts, etc. in order to improve the canal operation. In real situation, however, the progress is much slower, often much below acceptable levels. The reason may be due to technical gap, financial gap or social gap. It is 
therefore essential that operations should be as simple, as possible. The designer should think of ease of operation, frequent resetting of structures and complicated procedures should be avoided. In most of the irrigation projects maintenance activities are deferred because of inadequate recurrent funds. The lack of maintenance results in a rapid deterioration of public investments, including failure of canal lining and malfunctioning of control structures. The other aspects in canal water distribution are inequity in the pattern of water distribution. Head reach farmers often take advantage of their location and take an unfair share of water when the service is not reliable. Therefore the objective of this paper is to provide an improved scheduling programme which takes in to account all the above aspects.

\section{Equity planning in allocation}

In most of the Irrigation systems, the irrigation department is responsible for management of the system. At the beginning of the each season after ascertaining the water available in the reservoir, it announces the dates of water release to each of the outlets below the distributary. The department in the command area also announces the crop to be grown in each plot in the season before the starting of the season. However studies indicated that there is no control over the farmers by the system managers; hence violation of the cropping pattern is common in most of the canal system. (Venugopal. K, Ramaseshan. S, Ramesh. B.R (2005)). Hence prioritization of the water allocation is needed to attain equity in allocation. In the present methodology discussed in this paper, first priority is given to authorised plots which have adhered to the departmental notification. If the water is available further the water is allocated next to the plots under violation, In this, plots which are under dry crop is given first priority, since they require less water. Next priority is given the garden crop and last priority is given to wet crop. If further water is available it is allocated to unauthorised plots. Hence after knowing the areas of different crops under different category (authorized, violated.etc) water requirement of different crops can be found by Modified Penman's method (FAO Irrigation and Drainage Paper No. 56).since the crop water requirement differ in different stages of the crop, the total number of days the water supplied to the canal in the season is divided in to suitable period for computation of crop water requirement (Ex. If the number of days the canal supplied water in the season is 130 days, it can be divided in to 13 number of 10 day period block for crop water computation).

\section{Model Description}

Linear and Mixed integer linear programming are effectively used in scheduling irrigation canal (Anwar A. A., Clarke D.,(2001) De varies., Anwar A.A.,(2004)., Suryavanshi, A. R., and Reddy, J. M. (1986). Reddy, J. M., Wilamowski, B., and Sharmasarkar, F. C. (1999).). The present model is aimed at not only catering the demand of the laterals of the branch canal (wherein branch canal is supplied water continuously for whole season and laterals are to be controlled during the period (10 day block)) for the water requirement, but also operation of the laterals should be simple. It is decided to operate the laterals of the canal either full/half/closed condition on any day of the 10 day block. Hence The laterals are to be operated to cater this demand with the constraints (i) The sum of supplies to laterals on any day should be less than or equal to net daily supply in the canal.(ii)The sum of daily supply of the laterals for the complete period should be less than or equal to demand (iii)Other system constraints. Apart the laterals are to be supplied at minimum head of half supply capacity so that the water can reach the tail end. In the present stated operation scenario described above of the system, on any day during the period, all the laterals except one lateral will be running in full supply/half supply or closed condition. Zero-One programming model is developed for this operation policy with some modifications in the demand of the laterals. The demand modification is necessary as the laterals are to be operated either half/full/closed condition. Hence the demands of laterals for ten day period are rounded off to nearest value which is divisible by half supply capacity of the lateral (except of the lateral which is decided to operate at variable supply). Hence the demand of each lateral will be either little less or little more of their demand for the 10 day period. Cumulative excess water or deficit water available due to this adjustment is allocated to the lateral which is decided to run at variable supply. This modification does not deviate much from their original demand, if suitable lateral selected to run at variable discharge. Mixed integer linear programming model (Zero-One programming model) is used for daily operation scheduling model.

In this 0-1 integer-programming model the decision variable will be either "ZERO" or "ONE". The "ZERO" value of the decision variable may be represented as "OFF" condition of the lateral and value "ONE" as "ON" condition of the lateral.

The lateral on any day may be running at full supply or half supply or nil supply (closed). Hence, in this model three operating (full/half/closed) conditions of the lateral are to be integrated. Therefore, each lateral is imagined to comprise of two-sub channels with capacity equal to half the capacity of the lateral. A zero-one decision variable is defined for each of the sub channel of the lateral. The decision variable will take either 'ZERO' or 'ONE' on days of the period to represent 'OFF' or 'ON' condition of the sub channel respectively. The operating condition of the lateral on any day will be the sum of the decisions of the sub channels of the lateral

The sum of the supplies to laterals taking off from the branch canal on any day should be equal to net supply in the branch canal. This condition could be satisfied only when one of the laterals runs at variable supply. The decision 
variable of this lateral will be a continuous variable. Hence, the model comprises of one continuous variable for a lateral, which is decided to run at variable supply and 0-1 discrete variable for each sub channel with two-sub channel for each lateral representing all other laterals. Therefore, the model is a 'Mixed Integer Linear Programming' model. The formulation of the model is explained below.

The mixed integer linear programming formulation with following constraints and objective function are used for day wise allocation of the modified releases for the periods of each lateral.

Let $\mathrm{i}$ represents the lateral number, $\mathrm{j}$ the sub channel number, $\mathrm{k}$ the day number in the period. For formulation, the period is assumed as 10 days. Hence $\mathrm{k}$ will take value between 1 and 10 . Let $\mathrm{X}_{\mathrm{ijk}}$ represents the $0-1$ decision variable for $i^{\text {th }}$ lateral, $\mathrm{j}^{\text {th }}$ sub channel on $\mathrm{k}^{\text {th }}$ day.

$$
X_{i j k}=\left\{\begin{array}{cl}
0 & \text { when the sub channel } j \text { of } i^{\text {th }} \text { lateral is closed on } \mathrm{k}^{\text {th }} \text { day. } \\
1 & \text { when the sub channel } \mathrm{j} \text { of } \mathrm{i}^{\text {th }} \text { lateral is open on } \mathrm{k}^{\text {th }} \text { day. }
\end{array}\right.
$$

Let $\mathrm{v}$ represents the lateral number, which is proposed to run at variable supply. $\mathrm{X}_{\mathrm{vk}}$ is defined as a continuous variable in this model represents the supply in the $\mathrm{v}^{\text {th }}$ lateral on $\mathrm{k}^{\text {th }}$ day. Following constraints are used for the canal system

\subsection{Constraints:}

\subsubsection{Branch canal supply constraint}

The daily branch canal supply at the head of the canal is not constant for the complete period. It is gauged every day.

Hence the sum of the supplies to the laterals on any day should be less than or equal to net supply (Supply at the head of branch canal minus losses in branch canal) at the head of the branch canal. Mathematical representation of this constraint is as under.

$$
\sum_{\substack{i=1 \\ i \neq v}}^{n} \sum_{j=1}^{2} \frac{c_{i}}{2} X_{i j k}+X_{v k} \leq q_{k} \text { for } \mathrm{k}=1,2 \ldots \ldots 10
$$

Where,

$$
X_{i j k}= \begin{cases}0 & \text { when the sub channel } j \text { of } i^{\text {th }} \text { lateral is closed on } \mathrm{k}^{\text {th }} \text { day. } \\ 1 & \text { otherwise (i.e. when the sub channel } \mathrm{j} \text { of } \mathrm{i}^{\text {th }} \text { lateral is open on } \mathrm{k}^{\text {th }} \text { day) }\end{cases}
$$

$\mathrm{i}=$ Lateral number $=1,2 \ldots \ldots . \mathrm{n} ; \mathrm{v}=$ Lateral number proposed to run at variable supply $; \mathrm{n}=$ Number of laterals in the system $; c_{i}=$ capacity of the $\mathrm{i}^{\text {th }}$ lateral $($ cumec $)$

Since each lateral is imagined to comprise of two sub channel of capacity equal to half the lateral capacity, the term $\frac{c_{i}}{2} X_{i j k}$ represents the supply in the $\mathrm{j}^{\text {th }}$ sub channel of $\mathrm{i}^{\text {th }}$ lateral on $\mathrm{k}^{\text {th }}$ day in cumec-day.

$\mathrm{X}_{\mathrm{vk}}=$ supply in the $\mathrm{v}^{\text {th }}$ lateral on $\mathrm{k}^{\text {th }}$ day (cumec). This is a Continuous variable (i.e. the lateral $\mathrm{v}$ runs at variable supply). $; \mathrm{k}=$ Day number in the period. It is assumed ten day period is followed in this system hence $\mathrm{k}=1$, $2, \ldots \ldots \ldots 10 ; \mathrm{q}_{\mathrm{k}}=$ Net supply in the branch canal on $\mathrm{k}^{\text {th }}$ day (cumec) $=\mathrm{Q}-\mathrm{L}_{\mathrm{S}} ; \mathrm{Q}=$ Supply in the branch canal at the head (cumec) $; \mathrm{L}_{\mathrm{s}}=$ Branch canal seepage loss (cumec)

\subsubsection{Lateral demand constraint}

The supply to the lateral during any period should not exceed its modified releases for the period. This constraint is represented by

$$
\sum_{k=1}^{10} \sum_{j=1}^{2} \frac{c_{i}}{2} X_{i j k} \leq D_{i} \quad \text { for all } \mathrm{i}=1,2 \ldots \ldots \text { and } \mathrm{i} \neq \mathrm{v}
$$

and for lateral v running at variable supply 


$$
\sum_{k=1}^{10} X_{v k}<=\mathrm{D}_{\mathrm{v}}
$$

where $\mathrm{D}_{\mathrm{i}}=$ modified release of $\mathrm{i}^{\text {th }}$ lateral for the period (cumec-days); $\mathrm{D}_{\mathrm{v}}=$ modified release of the $\mathrm{v}^{\text {th }}$ (variable supply lateral) lateral for the period (cumec-days)

\subsubsection{Lateral capacity constraint}

On any day in the period, the supplies to lateral cannot exceed the capacity of the lateral.As the laterals are proposed to be operated at full/half/closed condition the total supply to lateral for the period will be in multiple of half capacity.

Each lateral is imagined to comprise of two sub channel of capacity equal to half the lateral capacity. The term $\frac{c_{i}}{2} X_{i j k}$ represents the supply in the $\mathrm{j}^{\text {th }}$ sub channel of $\mathrm{i}^{\text {th }}$ lateral on $\mathrm{k}^{\text {th }}$ day in cumecs. $\mathrm{X}_{\mathrm{ijk}}$ is a discrete decision variable takes value $0-1$ and $c_{i}$ represents the capacity of lateral $i$. The sum of supplies of two sub channels $(j=1$ and 2$)$ of $i^{\text {th }}$ lateral on $\mathrm{k}^{\text {th }}$ day gives the supply on $\mathrm{k}^{\text {th }}$ day of the period to $\mathrm{i}^{\text {th }}$ lateral. Hence declaring Xijk as a $0-1$ variable in the model can satisfy lateral capacity constraint.

One of the laterals in the system is proposed to be run at variable supply to adjust the daily supply in the branch canal. This lateral supply on any day of the period should be maintained at least or above half supply in order that lateral runs with sufficient depth of flow. This constraint is mathematically represented as below.

$$
\begin{aligned}
& \mathrm{X}_{\mathrm{vk}} \leq c_{v} \\
& \text { And } \quad \mathrm{X}_{\mathrm{vk}} \geq \frac{c_{v}}{2} \\
& \text { for all } \mathrm{k}=1,2 \ldots \ldots 10 \text { days. }
\end{aligned}
$$

\subsubsection{Branch canal sectional capacity constraint}

The cross section of branch canal is not constant in complete reach of the canal. Hence the flow in the branch canal at any section can't exceed the design capacity of the canal at that section. This constraint is formulated as follows.

The sum of the supplies to the laterals downstream of the section 's' (say) and the branch canal conveyance loss below this section on any day in the period, should not exceed the branch canal capacity at the section s.

If the section $\mathrm{s}$ is upstream of lateral $\mathrm{v}$ the constraint is written as

$$
\sum_{\substack{i=m_{s} \\ i \neq v}}^{n} \sum_{j=1}^{2} \frac{c_{i}}{2} X_{i j k}+X_{v k} \leq C_{s}-l_{s}
$$

for all $\mathrm{k}=1,2 \ldots . .10$

If the section $\mathrm{s}$ is down stream of lateral $\mathrm{v}$ the constraint is written as

$$
\sum_{i=m_{s}}^{n} \sum_{j=1}^{2} \frac{c_{i}}{2} X_{i j k} \leq C_{s}-l_{s}
$$

for all $\mathrm{k}=1,2 \ldots . .10$

where,

$\mathrm{m}=$ lateral number just downstream of the section $\mathrm{s}$.

$\mathrm{C}_{\mathrm{s}}=$ Capacity just below the section $\mathrm{s}$ in the branch canal (cumec)

$1_{\mathrm{s}}=$ seepage loss below the section (cumec) 
$\mathrm{s}=$ section in branch canal

\subsubsection{Objective Function}

The main objective of this MILP modeling is daily allocation of the net available water at the head of the branch canal to the laterals of the system in accordance with the modified releases for the period of the lateral, operation criteria of the lateral and the constraints cited above. Therefore, the objective function is defined as maximization of the total supply to the laterals for the period. If the constraints are all satisfied for the period the MILP objective function results will be equal to net supply at the head of the branch canal for the period. The mathematical representation of the objective function is,

$$
\text { Maximise } \sum_{k=1}^{10} \sum_{\substack{i=1 \\ i \neq v}}^{n} \sum_{j=1}^{2} \frac{c_{i}}{2} X_{i j k}+\sum_{k=1}^{10} X_{v k}
$$

where $X_{i j k}=$ discrete variable for $j^{\text {th }}$ sub channel of $i^{\text {th }}$ lateral on $\mathrm{k}^{\text {th }}$ day

$$
X_{\mathrm{ijk}}= \begin{cases}0 & \text { when the sub channel } \mathrm{j} \text { of } \mathrm{i}^{\text {th }} \text { lateral is closed on } \mathrm{k}^{\text {th }} \text { day. } \\ 1 & \text { otherwise }\end{cases}
$$

$\mathrm{c}_{\mathrm{i}}=$ capacity of $\mathrm{i}^{\text {th }}$ lateral

$\mathrm{X}_{\mathrm{vk}}=$ supply in $\mathrm{v}^{\text {th }}$ lateral on $\mathrm{k}^{\text {th }}$ day. ( $\mathrm{v}^{\text {th }}$ lateral runs at variable supply)

For illustration the model is applied to Harihar Branch canal of Bhadra canal system in Karnataka state.

\section{Illustration of model}

The Harihar branch canal is a sub system of Bhadra irrigation system in Karnataka state if India. It is designed for discharge capacity of $10.3 \mathrm{~m}^{3} / \mathrm{s}$. runs for length of $22 \mathrm{kms}$ and irrigates $14996 \mathrm{Ha}$. The canal irrigates both in Rabi (general period between January and June) and Kharif (general period between July and December) season. The branch canal comprise of 18 outlets/ distributaries. The details of the distributaries are shown in fig 1. For the analysis the cropping pattern of Kharif 2002 is considered. .During this season, the branch canal was operated continuously between $12^{\text {th }}$ July and $20^{\text {th }}$ November for 132 days. There were 13 periods. First and thirteenth periods were of 11 days and remaining periods are of 10 day periods. The crop water requirement of each lateral after prioritization is found for the period. The demand of each lateral of the period is rounded off to nearest half supply capacity, except of the lateral which is decided to run at variable supply ( Third lateral is decided to operate at variable supply). The model of daily scheduling of lateral is illustrated for third period of 10 days. Table 1 indicates the allocation procedure for the laterals of the distributary. The total supply for the period at the head of the Harihar branch canal on different days of the period and for ten days are indicated in column 2 is available for allocation to different laterals. The crop water requirement for authorised and violated crops (Dry crops were absent in this season) of different laterals are computed and are given in column 6 and column 7. After prioritization (i.e. water demand of laterals of authorised crops are met as first priorityfurther water available are proportionately allocated violated crops) demand of lateral for the period is shown in column 9.Modified demand of laterals after rounding off to nearest half supply capacity (except third lateral which is decided to operate at variable supply) is given in column 10. Hence the demands in the tenth column of different laterals are taken in the Mixed Integer Programming model. The programming model is run for the third period and the daily allocation to different model is given in Table 2. The model shows how the lateral is to be operated during the period to cater the demand. For example, the demand the lateral 1 is catered by keeping the lateral open on all days of the period. The demand of lateral 12 for the period is catered by operating the lateral at half on $1,2,7$ and $9^{\text {th }}$ day, full on $3,4,5,6$ and $8^{\text {th }}$ day and closed on $10^{\text {th }}$ day. Hence This methodology is quite simple and efficient operation schedule which can be adopted to any canal system.

\section{References}

Anwar A. A., Clarke D., (2001). Irrigation scheduling using mixed-integer linear programming. J Irrig. Drain. Engrg., Vol. 127, 63-69.

De varies., Anwar A.A., (2004). Irrigation Scheduling. I: Integer Programming Approach, J Irrig. Drain. Engrg., Vol 130, 9-16.

FAO Irrigation and Drainage Paper No. 56 Crop Evapotranspiration (guidelines for computing crop water requirements) - by Richard G. ALLEN. , Luis S. PEREIRA. Dirk RAES - Martin SMITH FAO, Water Resources, Development and Management Service Rome, Italy.

Reddy, J. M., Wilamowski, B., and Sharmasarkar, F. C. (1999). Optimal scheduling of irrigation for lateral canals. ICID 


\section{$J ., 48(3), 1-12$.}

Suryavanshi, A. R., and Reddy, J. M. (1986). Optimal operation schedule of irrigation distribution systems. Agric. Water Mgmt., Amsterdam, 11, 23-30.

Solanki.A.S. (2003). Equity issues and their socio-economic impact in a tribal dominated irrigation project of India http://www.aares.info/files/2003_solanki1.pdf

Venugopal .K, Ramaseshan .S, Ramesh. B.R (2005). A novel method of equitable allocation to laterals of irrigation channels in National Conference HYDRO-2005, 568-579.

Table 1. Allocation to laterals of Harihar Branch canal for Third Period

\begin{tabular}{|c|c|c|c|c|c|c|c|c|c|}
\hline 1 & 2 & 3 & 4 & 5 & 6 & 7 & 8 & 9 & 10 \\
\hline ڤે & 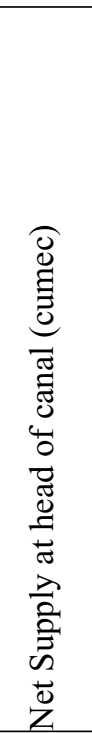 & 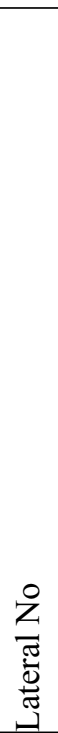 & 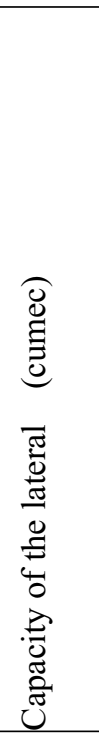 & 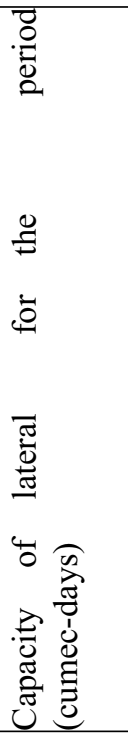 & 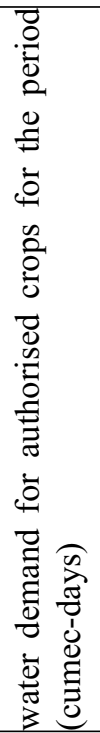 & 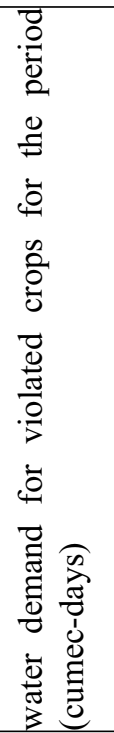 & 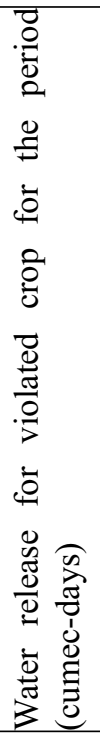 & 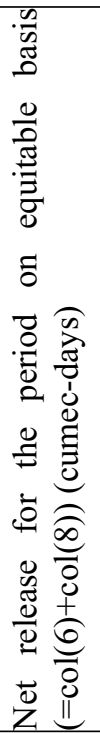 & 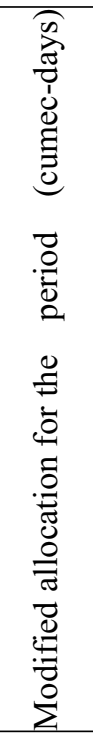 \\
\hline 1 & 8.7 & 1 & 1.19 & 11.89 & 1.40 & 16.21 & 10.49 & 11.89 & 11.89 \\
\hline 2 & 8.7 & 2 & 0.06 & 0.58 & 0.00 & 0.83 & 0.58 & 0.58 & 0.58 \\
\hline 3 & 8.7 & 3 & 1.84 & 18.41 & 0.00 & 17.29 & 15.58 & 15.58 & 15.94 \\
\hline 4 & 8.51 & 4 & 0.06 & 0.65 & 0.00 & 1.15 & 0.65 & 0.65 & 0.65 \\
\hline 5 & 8.7 & 5 & 0.25 & 2.47 & 0.00 & 2.50 & 2.26 & 2.26 & 2.22 \\
\hline 6 & 8.7 & 6 & 0.16 & 1.57 & 0.00 & 1.60 & 1.45 & 1.45 & 1.41 \\
\hline 7 & 8.7 & 7 & 0.11 & 1.11 & 0.00 & 1.78 & 1.11 & 1.11 & 1.11 \\
\hline 8 & 8.51 & 8 & 0.09 & 0.88 & 0.11 & 2.24 & 0.77 & 0.88 & 0.88 \\
\hline 9 & 8.7 & 9 & 0.08 & 0.80 & 0.00 & 0.51 & 0.46 & 0.46 & 0.48 \\
\hline \multirow[t]{10}{*}{10} & 8.51 & 10 & 1.76 & 17.65 & 1.10 & 31.43 & 16.55 & 17.65 & 17.65 \\
\hline & & 11 & 0.08 & 0.82 & 0.00 & 2.03 & 0.82 & 0.82 & 0.82 \\
\hline & & 12 & 0.25 & 2.50 & 0.14 & 1.83 & 1.65 & 1.79 & 1.75 \\
\hline & & 13 & 0.08 & 0.85 & 0.04 & 0.23 & 0.21 & 0.24 & 0.25 \\
\hline & & 14 & 0.05 & 0.49 & 0.07 & 0.99 & 0.42 & 0.49 & 0.49 \\
\hline & & 15 & 1.45 & 14.46 & 1.19 & 27.38 & 13.27 & 14.46 & 14.46 \\
\hline & & 16 & 1.24 & 12.38 & 0.75 & 0.86 & 0.77 & 1.52 & 1.24 \\
\hline & & 17 & 0.05 & 0.49 & 0.04 & 1.18 & 0.45 & 0.49 & 0.49 \\
\hline & & 18 & 1.41 & 14.10 & 0.00 & 25.96 & 14.10 & 14.10 & 14.10 \\
\hline & 86.42 & & 10.21 & 102.10 & 4.83 & 135.99 & 81.59 & 86.42 & 86.42 \\
\hline
\end{tabular}




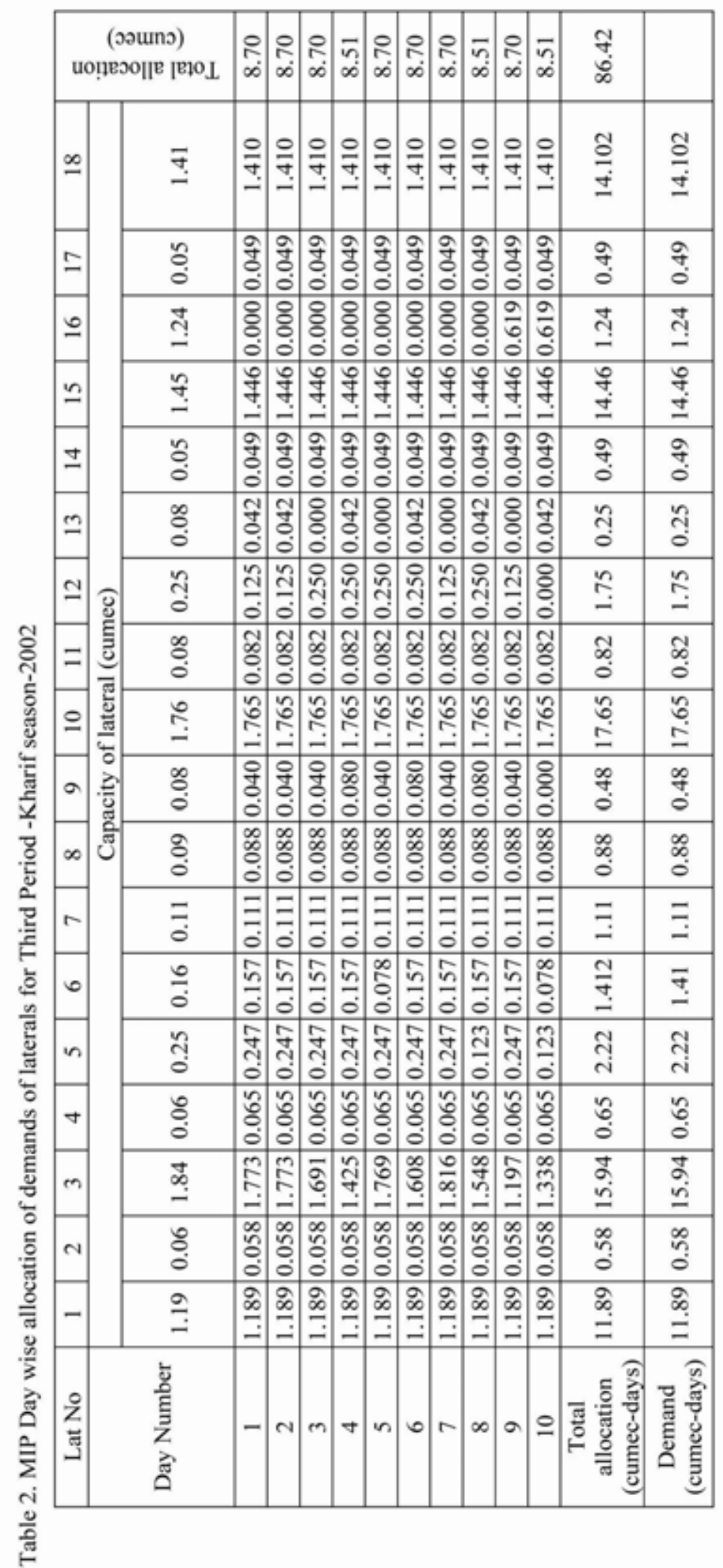




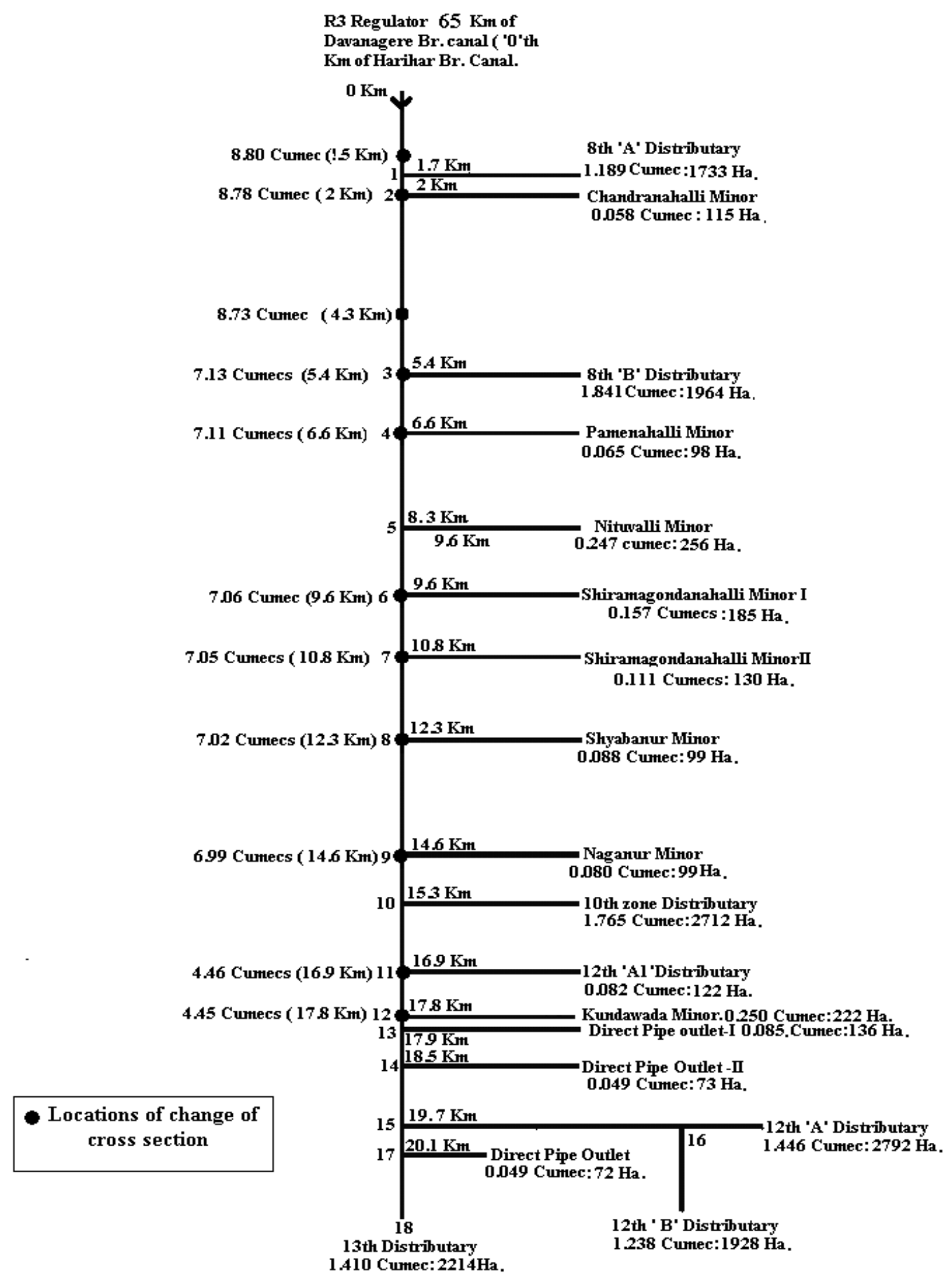

Figure 1. Tree Plan of with details of Harihar Branch Canal of Bhadra Command Area 